\title{
Comparison of TOPSIS and MAUT methods for recipient determination home surgery
}

\author{
Septya Maharani ${ }^{1}$, Holis Ridwanto ${ }^{2}$, Heliza Rahmania Hatta ${ }^{3}$, Dyna Marisa Khairina ${ }^{4}$, \\ Muhammad Rivani Ibrahim ${ }^{5}$ \\ 1,2,3,4 Department of Information System, Mulawarman University, Indonesia \\ ${ }^{5}$ Master of Information System, Diponegoro University, Indonesia
}

\begin{tabular}{l} 
Article Info \\
\hline Article history: \\
Received Mar 5, 2020 \\
Revised Jul 28, 2021 \\
Accepted Aug 10, 2021 \\
\hline Keywords: \\
Confusion matrix \\
Decision support system \\
Home surgery \\
MAUT \\
TOPSIS
\end{tabular}

Article history:

Received Mar 5, 2020

Revised Jul 28, 2021

Keywords:

Confusion matrix

Decision support system

MAUT

\begin{abstract}
House renovation is given by the government to the community, one of which is the assistance provided in the district. Long Mevery especially Tanah Abang Village, namely House Renovation Assistance. So, it is necessary to implement a DSS in determining the recipient of home renovation assistance by comparing multi-atribute utility theory (MAUT) method and TOPSIS to assist the government in determining the right home renovation assistance recipient. There are 16 criteria and their weight values. This study uses the multi-attribute utility theory (MAUT) method and the order of preference technique based on the similarity to the ideal solution (TOPSIS) as a calculation method to produce output and determine the level of accuracy of each method. The test in this study uses a confusion matrix and compares real data testing with the results of calculations on the system. The results of system testing using MAUT and TOPSIS methods, the accuracy of the MAUT method is $94.28 \%$ and the TOPSIS method is $35.71 \%$.
\end{abstract}

This is an open access article under the CC BY-SA license.

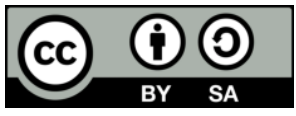

\section{Corresponding Author:}

Septya Maharani

Department of Information System

Mulawarman University

Sambaliung Road, Gunung Kelua Campus, Samarinda County, East Kalimantan, Indonesia

Email: septyamaharani@gmail.com

\section{INTRODUCTION}

Home renovation is a form of housing assistance given to the community that aims to be used for the sake of a comfortable and livable survival. Provision of Home Surgery is carried out selectively in accordance with established criteria. However, the acceptance of this assistance cannot yet be determined objectively so that it is not on target due to the large number of potential recipients as well as the criteria along with the weight in determining decisions. These problems are not in accordance with Law No. 13 of 2011 and Regulation of the Minister of Social Affairs of the Republic of Indonesia Number 20 of 2017 Concerning "Social Rehabilitation of Inadequate Houses and Environmental Infrastructure Facilities" [1]. So that the need for a computer technology-based decision system method in order to be able to calculate the number of criteria caused by the large number of prospective beneficiaries being recorded by the relevant agencies. In this study, researchers used the multi-attribute utility theory (MAUT) method and the technique for order of preference by similarity to ideal solution (TOPSIS) method, where the two methods will be compared to the level of accuracy when implemented in the case of the study with the aim of providing accurate recommendations. MAUT method is an ease in solving various decision-making problems based on attributes is one of the strengths of this method. And this provides an accurate and realistic result [2]. Based on comparative research conducted with the simple additive weighting and TOPSIS methods to support the selection decision for lecturer admissions [3] as well 
as the comparison of weighted product (WP) and MAUT methods in the support system for labor recruitment decision decisions [4]. The purpose of this study is to make a comparison between the MAUT and TOPSIS methods [5], [6] to find out which is more accurate and efficient and build a decision support system that compares the two methods for the selection of recipients of Home Surgery Assistance. This system is to help determine the decision of recipients of house renovation assistance in Long Mesangat District, specifically Tanah Abang Village, by comparing the MAUT method and the TOPSIS method. Comparison of methods is done to see which method is the best and approaching maximum results in accordance with existing criteria.

\section{RESEARCH METHOD}

\subsection{The technique for order of preference by similarity to ideal solution (TOPSIS)}

TOPSIS uses the principle that the chosen alternative must have the shortest distance from the positive ideal solution and the longest distance (the farthest) [7], from the negative ideal solution from a geometric point of view using the Euclidean distance (distance between two points) to determine the relative proximity of an alternative to the optimal solution [8], [9]. TOPSIS is based on the concept of where the alternative chosen is not only the best alternative because it has the shortest distance from the ideal solution, but also has the longest the distance from the negative ideal solution. The steps of the TOPSIS algorithm are as follows: Determining the ranking of each alternative TOPSIS requires a ranking of the performance of each alternative Ai on each normalized $\mathrm{Cj}$ criteria, namely:

$$
r_{i j}=\frac{x_{i j}}{\sqrt{\sum_{i=1}^{m} x_{i j}^{2}}}
$$

with $i=1.2, \ldots m$ and $j=1.2, \ldots n$.

Create a weighted normalized decision matrix (2):

$$
\mathrm{y}_{\mathrm{ij}}=\mathrm{w}_{\mathrm{i}} \cdot \mathrm{r}_{\mathrm{ij}}
$$

with $i=1,2 \ldots m$ and $j=1,2, \ldots . . n$.

Determine the ideal positive and negative solutions. The positive ideal solution $\mathrm{A}+$ and the negative ideal solution A- can be determined based on the normalized weight ranking as (3),

$$
\begin{aligned}
& A^{+}=\left(y_{1}^{+}, y_{2}^{+} \ldots \ldots, y_{n}^{+}\right) \\
& A^{-}=\left(y_{1}^{-}, y_{2}^{-} \ldots \ldots, y_{n}^{-}\right)
\end{aligned}
$$

Calculate distances with the ideal solution. Alternative distances with positive ideal solutions,

$$
D_{i}^{+}=\sqrt{\sum_{i=1}^{n}\left(y_{i}^{+}-y_{i j}\right)^{2}}
$$

Alternative distances with positive ideal solutions are calculated using the formula (6);

$$
D_{i}^{-}=\sqrt{\sum_{i=1}^{n}\left(y_{i j}-y_{i}^{-}\right)^{2}}
$$

Determine the preference value for each alternative. The preference value for each alternative is given as (7):

$$
V i=\frac{D_{i}^{-}}{D_{i}^{-}+D_{i}^{+}}
$$

\subsection{Multy atribute utility theory (MAUT)}

MAUT is a quantitative comparison method that usually combines measurement of different risk costs and benefits [10]. The MAUT method is used to convert several interests into numerical values on a scale of $0-1$ with 0 representing the worst value and 1 the best value [11]. The steps in the MAUT process are: Create a decision framework, by defining the problem, generate (generate) alternatives that might solve the problem, make a list of all aspects that influence the decision, give weight to every aspect that is there [12]. Existing weights must reflect how important these aspects are to the problem, give also the weight of the alternatives. For each alternative, determine how satisfying the alternative is for each aspect and The evaluation process of each alternative on the aspects that exist to get a decision. In the multi-attribute utility theory method, it is used

Comparison of TOPSIS and MAUT methods for recipient determination home surgery (Septya Maharani) 
to convert from multiple interests into numerical valueson a scale from $0-1$ with 0 representing the worst choice and 1 being the best [13], [14]. This allows a direct comparison of various measures. The overall evaluation value can be defined by (8):

$$
V_{(x)}=\sum_{i=1}^{n} w_{j} \cdot x_{i j}
$$

Matrix normalization in (9):

$$
U_{(x)}=\frac{x-x_{i}^{-}}{x_{i}^{+}-x_{i}^{-}}
$$

\subsection{Confusion matrix multi-class}

A confusion matrix [15]-[17]. That is, after a classifier has been trained, the confusion matrix produced by this classifier on a validation set could be used to find which classes present some confusion in the classification, and then a more specialised classification structure could be generated [18]. There are 4 (four) terms as a representation of the results of the classification process, the four terms are true positive (TP), true negative (TN), false positive (FP) and false negative (FN) [19]. True positive (TP) is the amount of positive data obtained correctly. True negative $(\mathrm{TN})$ value is the amount of negative data collected correctly. The confusion matrix model can be seen in Table 1 [20].

\begin{tabular}{ccc}
\multicolumn{2}{c}{ Table1. Model confusion matrix } \\
\hline Actual & \multicolumn{2}{c}{ Classified as } \\
& + & - \\
\hline+ & True Positive & False Negative \\
- & False Positive & True Negative \\
\hline
\end{tabular}

\subsection{Data collection and development system}

System development method in the case study of determining home surgery using a comparison of the MAUT method and TOPSIS using the Linear Sequential model or commonly called the Waterfall model [21]. This waterfall model process can be developed with research cases based on data requirements, design planning, implementation and the results of research in the form of a system to provide the expected results on This research is in the form of accuracy of the deadly method and the method of topsis for the determination of the recipient of home surgical assistance. The Waterfall method is a structured model, in which there are sequential stages of work and cannot repeat or continue if the previous stage has not been completed. The stages to be carried out by the waterfall model method [22], [23].

In Figure 1 shows in appendix, it starts with providing input in the form of 70 prospective recipients of data on home surgery assistance, and determining criteria. In this study, there were 16 criteria which weighed each criterion. Next, each criterion calculation uses each of the two methods MAUT and TOPSIS separately [24], [25]. After doing the calculations, a confussion Matrix test will be performed to obtain the value of accuracy, precision, and recall on each method. After that, an accurate method for this research case study will be obtained.

\section{RESULTS AND DISCUSSION}

\subsection{Data analysis}

Data analysis provides information on the criteria as material for selection in the form of numerical values in accordance with the results of interviews with the Head of the Long Mesangat District Government Section and the Head of Community Ability in Tanah Abang Village. In this research method, there are weights and criteria needed to determine the process of prospective recipients of Home Surgical Assistance. From the criteria determined there are weight values of 16 criteria reaching $100 \%$ with several rating groupings. Data analysis based on the results of interviews also obtained 70 sample data to be used in testing the system created. Sampling data is taken from the results of the manual recapitulation conducted by the Head of Community Welfare Affairs in Tanah Abang Village, Long Mesangat District in 2017 and 2018. The files obtained contain the identity of the community along with the verification score data that has been filled out by the Committee and Audit Team. In this Table 2 there are 16 criteria and Figure 2 the determined cost and benefit values as well as the appearance of criteria in the application that has been built.

Int J Artif Intell, Vol. 10, No. 4, December 2021: 930 - 937 
Table 2. Criteria for reconstruction of home surgery

\begin{tabular}{cclcc}
\hline No & Symbol & Criteria for Reconstruction of Home Surgery & Nature & Weight \\
\hline 1. & K1 & House Roof Model & Cost & 8 \\
2 & K2 & House Floor Model & Cost & 8 \\
3 & K3 & House Wall Model & Cost & 8 \\
4 & K4 & House Size Model & Cost & 8 \\
5 & K5 & Home Ownership Status & Benefit & 7 \\
6 & K6 & Status of Prospective Home Recipients & Benefit & 7 \\
7 & K7 & Monthly income & Cost & 7 \\
8 & K8 & Job Model & Cost & 7 \\
9 & K9 & The number of dependents & Benefit & 6 \\
10 & K10 & Electricity payment per month & Cost & 6 \\
11 & K11 & Monthly Water Payment & Cost & 6 \\
12 & K12 & Land and Building Tax Payment & Cost & 5 \\
13 & K13 & Garden Model & Cost & 5 \\
14 & K14 & Animal Models & Cost & 5 \\
15 & K15 & Electronic Model & Cost & 5 \\
16 & K16 & Vehicle Model & Cost & 5
\end{tabular}

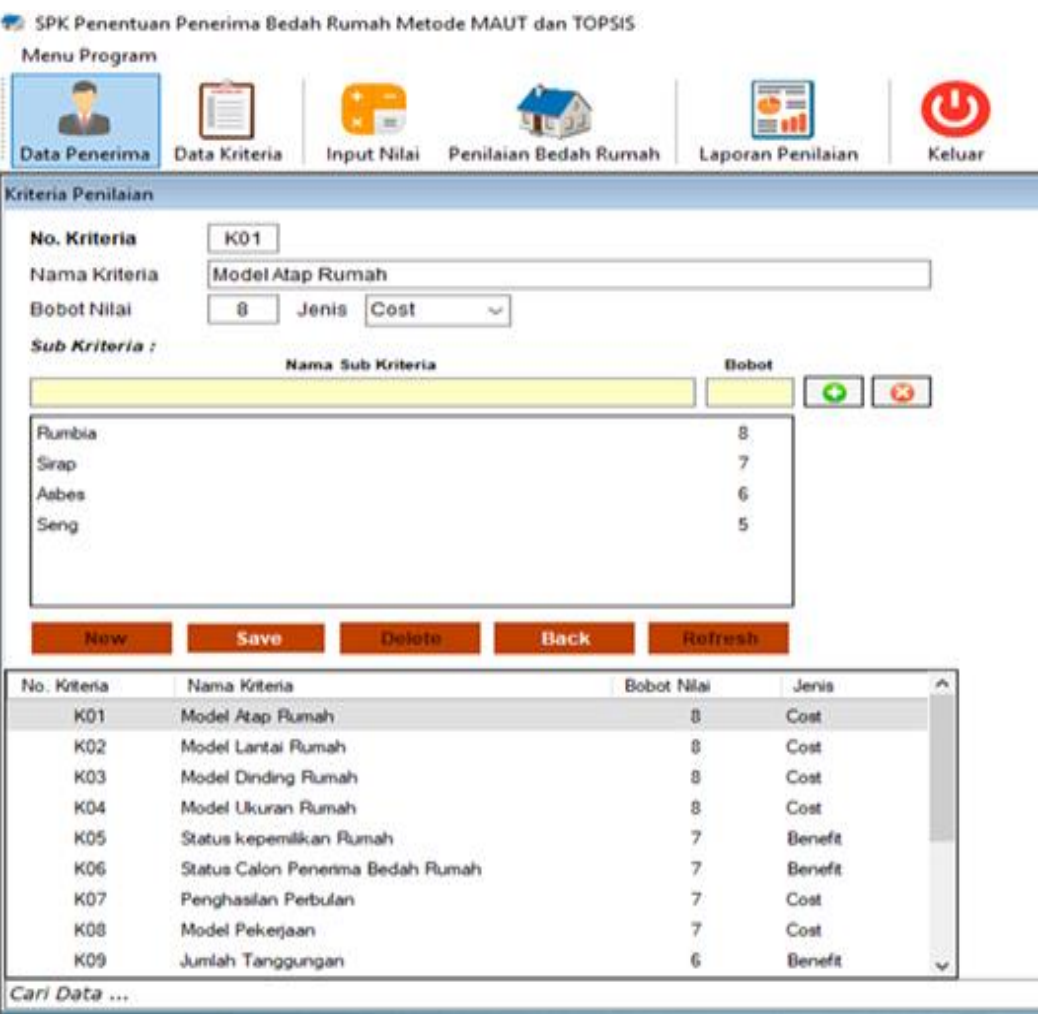

Figure 2. Display criteria and weight on DSS aplications

\subsection{Research results}

This study, has 16 criteria and each criterion has a weight value obtained from interviews with the Head of Community Welfare Affairs in Tanah Abang Village, Long Mesangat District, East Kutai, where 16 criteria are calculated along with 70 prospective recipients of data on house reconstruction assistance to be compared with the accuracy of the method MAUT and the TOPSIS Method. After getting the results of each MAUT and TOPSIS method calculations, proceed to test the level of accuracy using the confusion matrix test and to test the comparison of original data with the number of 70 prospective recipients of house surgery assistance with data that has been calculated using each of the two methods. Confusion matrix test results with each method are in the Tables 3 and 4.

The test results in Tables 3 and 4 using confussion martix show the accuracy value obtained by the MAUT method $92.28 \%$ between the value of the system test with the actual value, $97.56 \%$ precision of the accuracy of user requests with answers generated by the system, and recall 93, $02 \%$ success rate in finding back information. Whereas the TOPSIS method obtained an Accuracy value of $32.85 \%$ between the value of the test with the actual value, Precision $46.93 \%$ of the determination of the user's request with the answers

Comparison of TOPSIS and MAUT methods for recipient determination home surgery (Septya Maharani) 
generated by the system, and $53.48 \%$ recall rate of success in finding back an information. Based on the results of the calculation of the MAUT and TOPSIS methods, the results of the comparison between the original data and system testing can be seen in the Tables 5 and 6 the result comperasion of MAUT and TOPSIS method.

Table 3. Confussion matrix MAUT test result

\begin{tabular}{|c|c|c|c|c|c|}
\hline Type Of identification & $\begin{array}{l}\text { Test } \\
\text { data }\end{array}$ & $\mathrm{TP}$ & TN & FP & $\mathrm{FN}$ \\
\hline $\begin{array}{l}\text { Prospective recipient of } \\
\text { home surgery }\end{array}$ & 70 & 40 & 26 & 1 & 3 \\
\hline Accuracy & \multicolumn{5}{|c|}{$92,28 \%$} \\
\hline Precision & \multicolumn{5}{|c|}{$97,56 \%$} \\
\hline Recall & \multicolumn{5}{|c|}{$93,02 \%$} \\
\hline
\end{tabular}

Table 4. Confussion matrix TOPSIS test result

\begin{tabular}{cccccc}
\hline Type Of identification & $\begin{array}{c}\text { Test } \\
\text { data }\end{array}$ & TP & TN & FP & FN \\
\hline $\begin{array}{c}\text { Prospective recipient of } \\
\text { home surgery }\end{array}$ & 70 & 22 & 1 & 27 & 20 \\
Accuracy & & & & & \\
Precision & & $42,85 \%$ & & \\
Recall & & $53,93 \%$ & & \\
\end{tabular}

The results of comparison of original data with data managed by the system using the MAUT method and the TOPSIS method can be seen the difference in accuracy results that stand out from the two methods. The MAUT method reaches $94.28 \%$ while the TOPSIS method only reaches $32.85 \%$ of these results. It is known that the MAUT method is more accurate in processing data on the home surgical assistance recipient determination system. There are several factors that affect the accuracy of the TOPSIS method is lower, namely in the TOPSIS method there are grouping types of cost attribute criteria and benefits so that the results of manual calculations with the calculation of the TOPSIS method are inversely proportional. While in the MAUT method there is no grouping of types of criteria so that the results of the manual calculation with the results of the MAUT method are not much different.

Table 5. Comparison of MAUT and TOPSIS methods

\begin{tabular}{ccccc}
\hline No & Name & Original data results & MAUT method result & TOPSIS method result \\
\hline 1 & Juhana & Worthy & worthy & Not Feasible \\
2 & Adi Saepuloh & Not Feasible & Not Feasible & Worthy \\
3 & Asso & Worthy & Not Feasible & Worthy \\
4 & Pathullah & Not Feasible & Not Feasible & Worthy \\
5 & Arman & Not Feasible & Worthy & Not Feasible \\
6 & Hadi Sugito & Not Feasible & Not Feasible & Worthy \\
7 & Heri Firmansyah & Worthy & Worthy & Worthy \\
8 & Asnan & Not Feasible & Not Feasible & Worthy \\
9 & Hamsan & Worthy & Worthy & Worthy \\
10 & Rodi Asandi & Not Feasible & Not Feasible & Worthy \\
11 & Mahfuzin & Worthy & Worthy & Worthy \\
12 & Tajudin & Not Feasible & Not Feasible & Worthy \\
13 & Bayu & Worthy & Worthy & Worthy \\
$\cdot$ & $\cdot$ & $\cdot$ & $\cdot$ & $\cdot$ \\
. & $\cdot$ &. &. &. \\
$\ldots$ & $\ldots$ & $\ldots$ & $\ldots$ & $\ldots$ \\
68 & Jayadi & Not Feasible & Not Feasible & Worthy \\
69 & Sarmidi & Worthy & Worthy & Not Feasible \\
70 & Sholekhan & Worthy & Worthy & Worthy \\
\hline
\end{tabular}

Table 6. Comperasion of MAUT and TOPSIS methods

\begin{tabular}{cccc}
\hline Original data & Worthy & Not feasible & Amount \\
\hline Prospective recipient of home surgery & 42 & 28 & 70 \\
Calculation results For Accuracy & worthy & Not Feasible & Accuracy \\
MAUT & 40 & 30 & $94,28 \%$ \\
TOPSIS & 49 & 21 & $32,85 \%$ \\
\hline
\end{tabular}

\section{CONCLUSION}

Based on the results of research on the selection system for the acceptance of home surgical assistance, there are conclusions. Results from comparing the data of results of home surgery recipients with the results of the recommendation from the system is the application of the method MAUT in this case giving an accuracy result of $94.28 \%$. The application of the method TOPSIS in this case gives an accuracy result of $32.85 \%$ from 70 total data. Test results using confixion martix shows the accuracy value obtained by the MAUT method is $92.28 \%$ as the accuracy value, $97.56 \%$ precision value and given the success rate in finding an information of $93.02 \%$. While the TOPSIS method obtained an accuracy value of $32.85 \%$ between the test score and the actual 
value, precision $46.93 \%$ of determining user requests with answers generated by the system, and given the $53.48 \%$ success rate in rediscovering information. The high accuracy of the method MAUT is due in original data from the Head of Public Welfare Affairs perform the calculation process by adding up the entire score without grouping the type of benefit or cost criteria the same as the MAUT method calculation, so the results of the calculation are not much different. The low accuracy of the TOPSIS method is because in the original data from the Head of Public Welfare Affairs Mr. Hidayatullah there was no grouping of the type of criteria namely benefits and costs so that the calculation results are inversely proportional. So from the result of the test that have been Carried out, The MAUT method is more accurate to provide recommendations on the determination of home surgical recipients.

\section{APPENDIX}

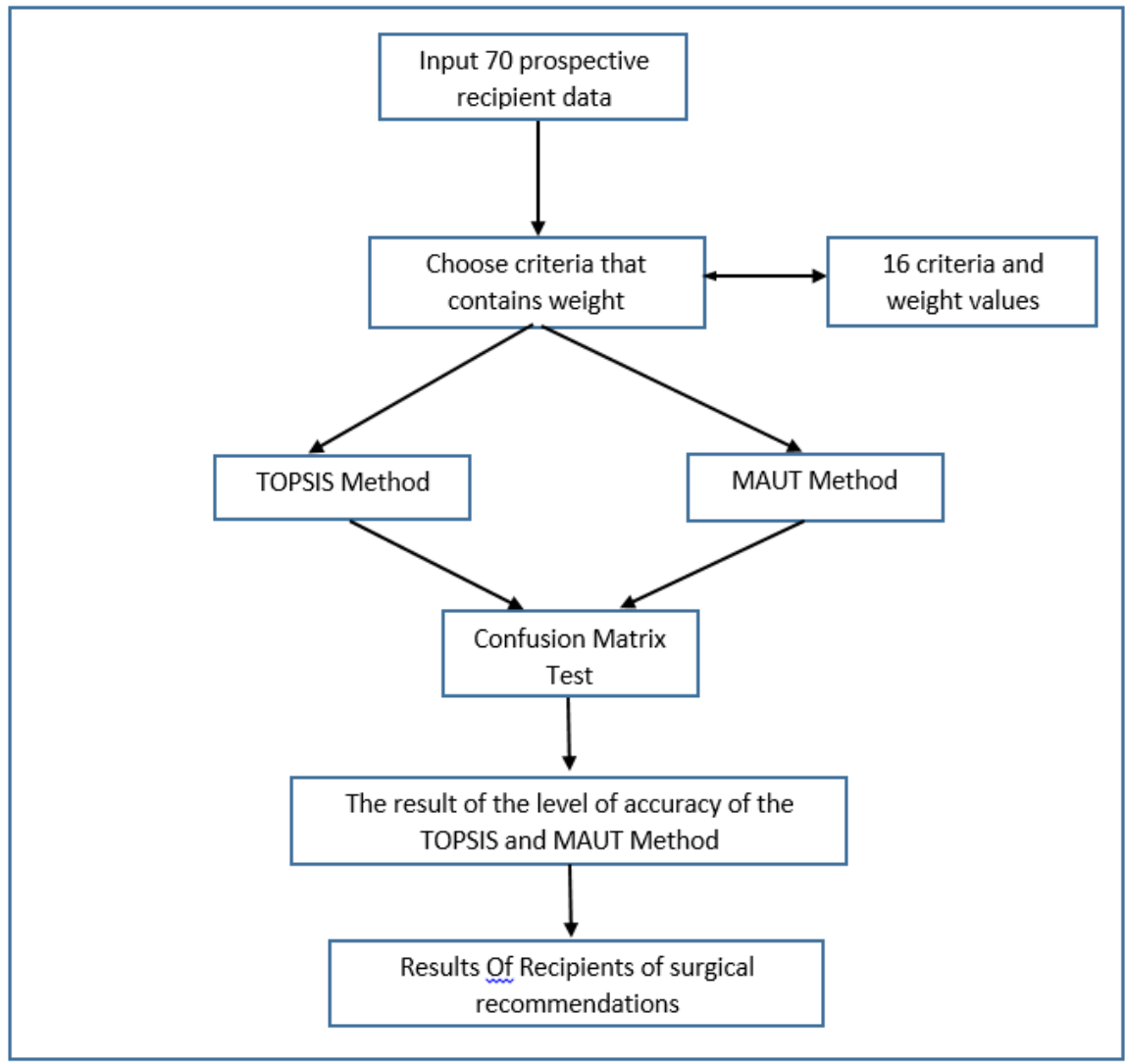

Figure 1. System acceptance of home surgical assistance

\section{REFERENCES}

[1] H. Altin, "A comparative analysis of CE-Topsis and CE-Maut methods," International Journal of Strategic Decision Sciences (IJSDS), vol. 11, no. 3, pp. 18-51, 2020, doi: 10.4018/IJSDS.2020070102

[2] A. Alinezhad and J. Khalili, "MAUT method in: New methods and applications in multiple attribute decision making (MADM)," Springer International Publishing, vol. 277, 2019, doi: 10.1007/978-3-030-15009-9.

[3] A. Arifin, Y. Gemilang, S. Kusumadewi, and H. Wahyuningsih, "The group decision support model to determine the level of depression among married couple," Proceedings of the 1st International Conference on Science and Technology for an Internet of Things, Yogyakarta, Indonesia, 2018, doi: 10.4108/eai.19-10-2018.2281306.

[4] D. M. Khairina, Ramadiani, S. Sahamur, A. Suyatno, S. Maharani and H. R. Hatta, "Assessment of teacher performance using technique for other preference by similarity to ideal solution (TOPSIS)," 2018 Third International Conference on Informatics and Computing (ICIC), 2018, pp. 1-6, doi: 10.1109/IAC.2018.8780452.

[5] F. W. Nugraha, S. Fauziati and A. E. Permanasari, "Combination of fuzzy c-means and simple additive weighting using partition coefficient index," 2020 Third International Conference on Vocational Education and Electrical Engineering (ICVEE), 2020, pp. 1-5, doi: 10.1109/ICVEE50212.2020.9243282.

[6] H.-S. Shih, H.-J. Shyur, and E. S. Lee, "An extension of TOPSIS for group decision making," Mathematical and Computer Modelling, vol. 45, no. 7-8, pp. 801-813, 2007, doi: 10.1016/j.mcm.2006.03.023. 
[7] M. Abdel-Basset, G, Manogaran, A. Gamal and F. Smarandache, "A group decision making framework based on neutrosophic TOPSIS approach for smart medical device selection. Journal of medical systems, vol. 43, no. 2, 2019, doi: 10.1007/s10916-019-1156-1

[8] Joshi. D and Kumar. S, "Intuitionistic fuzzy entropy and distance measure based TOPSIS method for multi-criteria decision making," Egyptian informatics journal, vol. 15, no. 2, pp. 97-104, 2014, doi: 10.1016/j.eij.2014.03.002.

[9] S. P. Nooka, S. Chennupati, K. Veerabhadra, S. Sah and R. Ptucha, "Adaptive hierarchical classification networks," 23rd Int. Conference on Pattern Recognition (ICPR), 2016, pp. 3578-3583, doi: 10.1109/ICPR.2016.7900189.

[10] Safrizal. L. Tanti, R. Puspasari and B. Triandi, "Employee performance assessment with profile matching method," 2018 6th International Conference on Cyber and IT Service Management (CITSM), 2018, pp. 1-6, doi: 10.1109/CITSM.2018.8674256.

[11] Z. Allah Bukhsh, I, Stipanovic and A. G. Doree, "Multi-year maintenance planning framework using multi-attribute utility theory and genetic algorithms," Eur. Transp. Res. Rev. vol. 12, no. 3, 2020, doi: 10.1186/s12544-019-0388-y.

[12] S. Anindita and D. M. Khairina, "Model assessment of land suitability decision making for oil palm plantation," 2016 2nd International Conference on Science in Information Technology (ICSITech), 2016, pp. 109-113, doi: 10.1109/ICSITech.2016.7852617.

[13] C. Chetna, P. K. Kapur, S. K. Khatri, R. Muthukumar, and A. K. Shrivastava, "Effort based release time of software for detection and correction processes using MAUT," International Journal of System Assurance Engineering and Management, vol. 11, pp. 367-378, 2020, doi: 10.1007/s13198-020-00955-2.

[14] H. Gunawan, H. Ramadhan, "Increased accuracy of selection high performing employees using multi attribute utility theory (MAUT)," 2018 6th International Conference on Cyber and IT Service Management (CITSM), 2018, pp. 1-4, doi: 10.1109/CITSM.2018.8674060.

[15] M. Hasnain, M. F. Pasha, I. Ghani, M. Imran, M. Y. Alzahrani and R. Budiarto, "Evaluating trust prediction and confusion matrix measures for web services ranking," in IEEE Access, vol. 8, pp. 90847-90861, 2020, doi: 10.1109/ACCESS.2020.2994222.

[16] C. Ta-Chung, and M. Kysely, "Ranking objectives of advertisements on Facebook by a fuzzy TOPSIS method," Electronic Commerce Research, pp. 1-36, 2020, doi: 10.1007/s10660-019-09394-z

[17] P. Cavalin, and L. Oliveira, "Confusion matrix-based building of hierarchical classification," Iberoamerican Congress on Pattern Recognition, vol. 11401, pp. 271-278, 2019, doi: 10.1007/978-3-030-13469-3_32.

[18] T. Mauritsius, S. Alatas, F. Binsar, R. Jayadi and N. Legowo, "Promo abuse modeling in e-commerce using machine learning approach," 2020 8th International Conference on Orange Technology (ICOT), 2020, pp. 1-6, doi: 10.1109/ICOT51877.2020.9468744.

[19] N. Umar and B. E. W. Asrul, "Implementation of TOPSIS methods in determining Makassar special culinary business location," 2018 2nd East Indonesia Conference on Computer and Information Technology (EIConCIT), 2018, pp. 82-85, doi: 10.1109/EIConCIT.2018.8878597.

[20] Chaubey. G, Bisen. D, Arjaria. S, “Thyroid disease prediction using machine learning approaches," Natl. Acad. Sci. Lett, vol. 44, pp. 233-238, 2021, https://doi.org/10.1007/s40009-020-00979-z.

[21] T. Thesing, T. Feldmann, M. Burchardt, "Agile versus waterfall project management: decision model for selecting the appropriate approach to a project," Procedia Computer Science, vol. 181, pp. 746-756, 2021, doi: 10.1016/j.procs.2021.01.227.

[22] D. M. Khairina, S. Maharani, H. R. Hatta, "Decision support system for admission selection and positioning human resources by using naive bayes method," Advanced Science Letters, vol. 23, no. 3, pp. 2495-2497, 2017, doi: 10.1166/asl.2017.8653.

[23] R. Ramadiani, H. R. Hatta, N. Novita and Azainil, "Comparison of two methods between TOPSIS and MAUT in determining BIDIKMISI scholarship," 2018 Third International Conference on Informatics and Computing (ICIC), 2018, pp. 1-6, doi: 10.1109/IAC.2018.8780455.

[24] A. E. Youssef, "An integrated MCDM approach for cloud service selection based on TOPSIS and BWM," in IEEE Access, vol. 8, pp. 71851-71865, 2020, doi: 10.1109/ACCESS.2020.2987111.

[25] N. Umar and B. E. W. Asrul, "Implementation of TOPSIS methods in determining makassar special culinary business location," 2018 2nd East Indonesia Conference on Computer and Information Technology (EIConCIT), 2018, pp. 82-85, doi: 10.1109/EIConCIT.2018.8878597.

\section{BIOGRAPHIES OF AUTHORS}

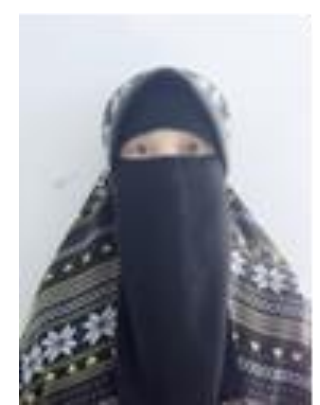

Septya Maharani, Born September 29th, 1984 in Samarinda, received Bachelor of Information System from Mulawarman University. Master of Information System from Universitas Diponogoro, Semarang, Indonesia in 2012. Currently her is a lecturer at Department of Computer Science in Mulawarman University, Samarinda, East Kalimantan, Indonesia. His research areas of interest are decision support system, expert system, information system and computer and human. Email: septyamaharani@yahoo.com

Int J Artif Intell, Vol. 10, No. 4, December 2021: 930 - 937 

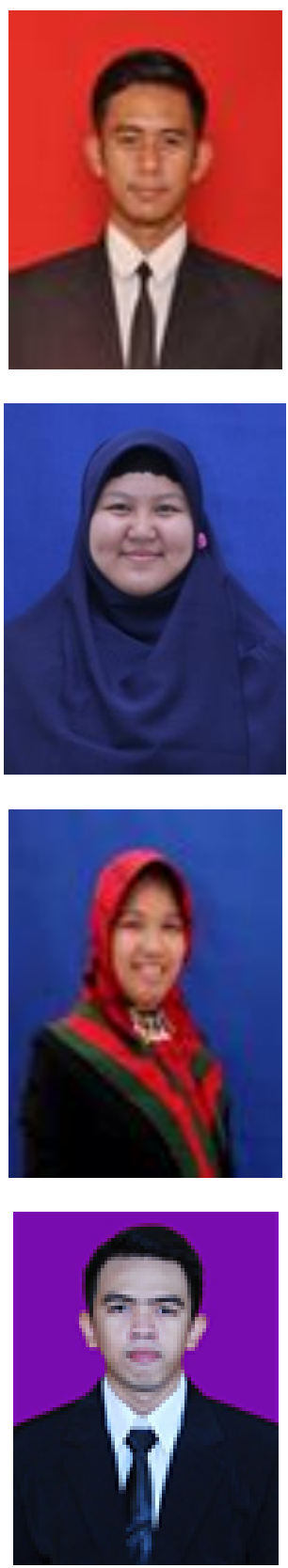

Holis Ridwanto, was born in Long Mesangat, East Kalimantan, Indonesia in September 20th, 1997. He received her Bachelor degree in Computer Science of Universitas Mulawarman, Indonesia in 2016. His research interest are information system and decision support system. Email: muhammadholis07@gmail.com

Heliza Rahmania Hatta, Born July 15th, 1985 in Samarinda, received Bachelor of Computer Science from Mulawarman University. Master of Informatics Engineering from In Institut Teknologi Sepuluh Nopember, Surabaya, Indonesia in 2013. Currently her is a lecturer at Department of Computer Science in Mulawarman University, Samarinda, East Kalimantan, Indonesia. His research areas of interest are artificial intelligence, decision support system, expert system, information system and information technology.

Email: heliza_rahmania@yahoo.com

Dyna Marisa Khairina, was born in Samarinda, East Kalimantan, Indonesia in Maret 5th, 1984. She received her Bachelor degree in Computer Science of Universitas Mulawarman, Indonesia in 2007. She received her Master of Information System degree at Universitas Diponegoro, Semarang, Indonesia in 2012. She is working as a lecture in the department of Computer Science Universitas Mulawarman, Samarinda, Indonesia since 2008. Her research interest are information system and decision support system. Email: dyna.ilkom@yahoo.com

Muhammad Rivani Ibrahim, was born in Samarinda, East Kalimantan, Indonesia in May 24th, 1994. He received her Bachelor degree in Computer Science of Universitas Mulawarman, Indonesia in 2016. His research interest are information system and decision support system. Email: rvn.ilkom@gmail.com. 